\title{
PFR model and GiT for landslide susceptibility mapping: a case study from Central Alborz, Iran
}

\begin{abstract}
In northern parts of Iran such as the Alborz Mountain belt, frequent landslides occur due to a combination of climate and geologic conditions with high tectonic activities. This results in millions of dollars of financial damages annually excluding casualties and unrecoverable resources. This paper evaluates the landslide susceptible areas in Central Alborz using the probabilistic frequency ratio (PFR) model and Geo-information Technology (GiT). The landslide location map in this study has been generated based on image elements interpreted from IRS satellite data and field observations. The display, manipulation and analysis have been carried out to evaluate layers such as geology, geomorphology, soil, slope, aspect, land use, distance from faults, lineaments, roads and drainages. The validation group of actual landslides and relative operation curve method has been used to increase the accuracy of the final landslide susceptibility map. The area under the curve evaluates how well the method predicts landslides. The results showed a satisfactory agreement of $91 \%$ between prepared susceptibility map and existing data on landslide locations.
\end{abstract}

Keyword: Central Alborz; Landslide; Probabilistic frequency ratio; Susceptibility 